\title{
The effect of diode laser irradiation associated with photoabsorbing agents containing remineralizing materials on microhardness, morphology and chemical structure of early enamel caries
}

\author{
Farzaneh Ahrari ${ }^{1}$, Hamideh-Sadat Mohammadipour ${ }^{2}$, Ladan Hajimomenian ${ }^{3}$, Amir Fallah-Rastegar ${ }^{3}$ \\ ${ }^{1}$ Assistant Professor of Orthodontics, Dental Research Center, School of Dentistry, Mashhad University of Medical Sciences, \\ Mashhad, Iran \\ ${ }^{2}$ Assistant Professor of Restorative Dentistry, Department of Restorative and Cosmetic Dentistry, School of Dentistry, Mashhad \\ University of Medical Sciences, Mashhad, Iran \\ ${ }^{3}$ Dental Research Center, School of Dentistry, Mashhad University of Medical Sciences, Mashhad, Iran
}

Correspondence:

Department of Restorative and Cosmetic Dentistry

School of Dentistry

Mashhad University of Medical Sciences

Vakilabad Boulevard, Mashhad, Iran

Mohammadipourh@mums.ac.ir

Ahrari F, Mohammadipour HS, Hajimomenian L, Fallah-Rastegar A. The
effect of diode laser irradiation associated with photoabsorbing agents con-
taining remineralizing materials on microhardness, morphology and chem-
ical structure of early enamel caries. J Clin Exp Dent. 2018;10(10):e955-
62.
http://www.medicinaoral.com/odo/volumenes/v10i10/jcedv10i10p955.pdf

Received: 31/05/2018 Accepted: 05/07/2018

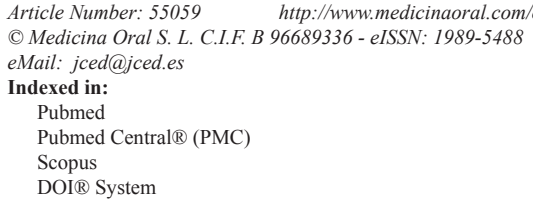

\begin{abstract}
Background: This study investigated the effects of laser irradiation associated with photo-absorbing agents containing sodium fluoride $(\mathrm{NaF})$, MI paste Plus or Remin Pro ${ }^{\circledR}$ on microhardness and surface structure of white spot lesions (WSLs).

Material and Methods: Fifty-six premolars were divided into two halves, then immersed in a demineraling solution to induce WSLs. The samples were divided into 8 groups by treatment $(\mathrm{n}=12)$ : (1) control, (2) diode laser $(810 \mathrm{~nm}$, $500 \mathrm{~mW}, 90$ s), (3) NaF, (4) MI Paste plus, (5) Remin Pro®, (6) NaF + Laser, (7) MI Paste Plus + Laser, (8) Remin Pro ${ }+$ Laser. Microhardness was measured before and after remineralization treatments. Two samples from each group were selected for SEM analysis.

Results: Microhardness increased significantly after all treatments with the exception of control, Laser and Remin Pro ${ }^{\circ}$ groups $(p>0.05)$. ANOVA revealed no significant difference in initial microhardness $(\mathrm{P}=0.21)$, whereas a significant difference was noted after treatment $(P=0.009)$. The application of sodium fluoride with or without laser irradiation produced the highest microhardness among the groups $(p<0.05)$. SEM analysis revealed some cracks on lased enamel and non-homogenous coatings of minerals after the use of remineralizing products.

Conclusions: The use of $\mathrm{NaF}$ either alone or combined with laser irradiation was the most effecttive strategy for increasing microhardness of WSLs. The application of diode laser through photoabsorbing agents containing sodium fluoride or MI Paste Plus did not produce any additional effects in enhancing remineralization of WSLs, whereas the combined application of diode laser with Remin Pro ${ }^{\circledR}$ was effective.
\end{abstract}

Key words: CPP-ACP, Enamel caries, fluoride, Hydroxyapatite, Low level laser, Microhardness, Remineralization, casein phosphopeptide amorphous calcium phosphate. 


\section{Introduction}

The earliest manifestation of dental caries is the production of subsurface porosities which lead to a milky-white appearance on the tooth surface, defined as white spot lesions (WSs). These lesions are more frequently observed in patients who have poor dental hygiene or in those undergoing fixed orthodontic treatment. WSLs not only produce an unaesthetic and disturbing appearance, but also can progress to caries cavities on the tooth surface $(1,2)$.

The WSLs can be remineralized before surface cavitations through diffusion of fluoride, calcium and phosphate ions from remineralizing agents into their structure (3). Other remineralizing products such as casein phosphopeptide amorphous calcium phosphate (CPP$\mathrm{ACP}$ ) and hydroxyapatite have also been proposed in recent years for the prevention and treatment of caries affected surfaces. MI Paste Plus (GC Corporation, Tokyo, Japan) is a commercial product that contains CPPACP and 900 ppm fluoride (CPP-ACPF). Remin Pro ${ }^{\circledR}$ (VOCO GmbH, Cuxhaven, Germany) is another remineralizing cream containing hydroxyapatite, fluoride and xylitol. Previous studies reported promising results on the use of products containing CPP-ACP or hydroxyapatite for caries management (4-8). Uysal et al. (9) indicated that the effectiveness of CPP-ACP in inhibiting caries around orthodontic brackets was comparable to sodium fluoride. Bilgin et al. (4) exhibited that Remin Pro $\AA$ produced a greater remineralization effect on enamel WSLs compared to CPP-ACPF, sodium fluoride and fluoride varnish.

Laser irradiation has been applied in recent years for its possible strengthening effect on tooth structure. It has been indicated that high power lasers such as $\mathrm{CO}_{2}$ laser can increase enamel surface hardness and reduce its solubility $(2,10,11)$. However, high power lasers should be applied consciously and with low energy level to preserve enamel integrity and minimize the creation of porosities on the tooth surface (12). Low-power red and near-infrared lasers appear to be a tempting alternative to high power lasers for caries inhibition (3). However, there are only a few studies regarding the use of low power lasers for prevention and management of dental caries (13-16).

To alter the composition or solubility of enamel, the laser energy must be strongly absorbed and converted into heat without damage to tooth structure or surrounding tissues (3). The application of photo-absorbing agents have been suggested before irradiation of low power lasers to accumulate laser energy and increase its thermal effects. On the other hand, it has been indicated that the application of topical mineral agents combined with laser irradiatin produces a synergistic effect on caries treatment and reduces enamel solubility and permeability $(2,10,12)$. Therefore, the photo-absorbing creams can be mixed with remineralizing agents for better remineralizing effects.

To our knowledge, no study investigated the effect of photo-absorbing creams containing remineralizing agents followed by low level laser irradiation on microhardness of WSLs. Therefore, this in vitro study was conducted to evaluate the effect of low power laser irradiation associated with photo-absorbing creams containing $2 \%$ sodium fluoride, MI paste Plus or Remin Pro ${ }^{\circledR}$ on microhardness, surface structure and chemical composition of WSLs.

\section{Material and Methods}

-Sample selection and preparation

In this in vitro study, 56 sound premolars extracted for orthodontic reasons were selected. Remained soft tissues, calculus and plaque were removed by hand instruments, rubber cap and pumice slurry from the tooth surfaces. The cleaned teeth were examined under a stereomicroscope (Dino lite Pro, Anmo Electronics Corp, Taiwan) at $10 \mathrm{X}$ magnification to discard those with caries, cracks and developmental and structural defects in enamel structure. The selected teeth were then stored in a $0.1 \%$ thymol solution at room temperature until the time of the experiment. For sample preparation, the root of the tooth was separated, and the crown was bisected in mesiodistal direction into two halves, using a slow-speed water-cooled diamond saw (CNC Machine, Nemo, Iran). Therefore, two blocks were obtained from each tooth, one from the buccal and the other one from the lingual surface. Afterwards, the blocks were embedded in epoxy resin, in such a way that the buccal/lingual enamel was positioned horizontally, in contact with the working table. A treatment window of $4 \times 4 \mathrm{~mm}$ was then exposed on the surface of each specimen, using 400, 600 and 800 grit silicon carbide papers. Finally, a random number was given to each resin block.

To induce artificial white spot lesions (WSLs), the samples were stored individually for 10 weeks in plastic containers, filled with a demineralizing solution. This solution consisted of $50 \mathrm{mM}$ acetic acid, $2.2 \mathrm{mM} \mathrm{CaCl}_{2}$, and $2.2 \mathrm{mM} \mathrm{NaH}_{2} \mathrm{PO}_{4}$ with $\mathrm{pH}$ adjusted at 4.8 using potassium hydroxide $(\mathrm{KOH})$. The demineralizing solution was replaced every five days. The presence of WSLs was confirmed visually in all the specimens by a magnifier.

-Surface microhardness measurement

The specimens were rinsed with distilled water and airdried for $30 \mathrm{~s}$. The initial microhardness number of each sample was measured using a Vickers microhardness tester (Matsuzawa, Japan). The indentor of the device was placed perpendicular to the early enamel caries surface. A vertical load of $100 \mathrm{~g}$ was applied for $5 \mathrm{~s}$, and the indentation length was photographed and measured using a microscope and computer software. The test was 
performed at three close areas on each specimen and the mean value was calculated.

-Surface treatments

The enamel blocks were randomly assigned to eight groups $(\mathrm{n}=12)$, according to the treatment applied on demineralized enamel:

Group1 (control): No treatment was performed and the samples were immersed in distilled water.

Group 2 (Laser): The specimens in this group were irradiated by an infrared gallium aluminum arsenide (GaAlAs) diode laser (wavelength $810 \mathrm{~nm}$; ARC Laser $\mathrm{GmbH}$, Nürnberg, Germany). The beam was delivered perpendicularly through a $300 \mu \mathrm{m}$ fiber optic cable at continuous-wave mode for 90 seconds. The power was set at $500 \mathrm{~mW}$ and the laser irradiation was performed with a light contact and sweeping motion to ensure covering the whole surface of the window.

Group 3 (NaF): A 2\% sodium fluoride gel (Sultan Health Care Inc., Englewood, New Jersey, USA) was applied on enamel surface and remained for 5 minutes; then thoroughly rinsed with running water. The specimens were then stored in distilled water.

Group 4 (MI Paste Plus): The treatment windows were covered with a sufficient amount of MI Paste Plus (Recaldent, GC, Japan) containing CPP-ACPF for 5 minutes. The specimens were then rinsed and stored in distilled water.

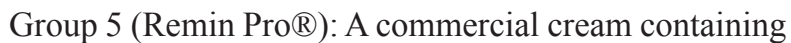

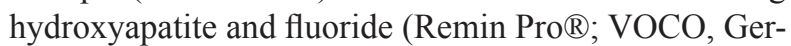
many) was applied on the enamel surface and remained for 5 minutes; then thoroughly rinsed with running water and the specimens were immersed in distilled water.

Group $6(\mathrm{NaF}+$ Laser): A photo-absorbing $\mathrm{NaF}$ agent was prepared by adding a blue eatable dye to $\mathrm{NaF}$ gel to increase laser absorption. The gel was placed on the enamel surface and the diode laser was irradiated immediately for 90 seconds through the gel using the parameters described beforehand. After 5 minutes of applying the photo-absorbing gel, the specimens were rinsed and immersed in distilled water.

Group 7 (MI Paste Plus + Laser): A photo-absorbing cream containing CPP-ACPF was prepared by adding a blue eatable dye to MI Paste Plus. The cream was placed on the enamel surface and the treatment sequence was followed similar to group 6 .

Group 8 (Remin Pro ${ }^{\circledR}+$ Laser): A photo-absorbing agent containing hydroxyapatite and fluoride was made by adding a blue eatable dye to Remin Pro ${ }^{\circledR}$. The cream was then placed on the enamel surface and the treatment sequence was continued similar to group 6 .

Afterwards, the specimens were again subjected to microhardness assessment. The test was performed under the same conditions as described beforehand, and the mean value of three measurements was recorded for each specimen.
-Scanning Electron Microscopy (SEM) and Energy Dispersing X-ray (EDX) analysis

Two samples from each group were randomly selected to assess the surface morphology and chemical alteration of enamel after different surface treatments.

The surface morphology of the specimens was analyzed using a scanning electron microscope (SEM, VEGA II LSH, TESCAN, Czech Republic) at $\times 1000$ magnifications. The samples were desiccated using $100 \%$ alcohol, and then coated with a thin film of gold for SEM examination.

The chemical composition of the specimens was evaluated using an EDX detector that was applied by an energy dispersion X-ray spectrophotometer (QUANTAX QX2, BRUKER/ROENTEC, Germany). The calcium, phosphate and fluoride contents were recorded in weight percent of the specimen.

-Statistical analysis

The normal distribution of the data was confirmed by the Kolmogorov-Smirnov test. A paired sample t-test was applied to determine any significant alteration in microhardness values before and after treatment in each of the study groups. One way analysis of variance (ANOVA) was run to detect any significant difference in microhardness values among the study groups either before or after treatment. When a significant difference was noted, pairwise comparisons were made by Duncan pot hoc test. The data were analyzed through SPSS software (Statistical Package for Social Sciences, Version 16.0, SPSS Inc, Chicago, Ill, USA) and the significance level was determined at $p<0.05$.

\section{Results}

The results obtained from the paired sample t-test indicated that microhardness values increased significantly after all treatments with the exception of control (group 1), Laser (group 2) and Remin Pro® (group 6) groups, which showed no significant difference after treatment $(P>0.05)$.

ANOVA revealed no significant difference in initial microhardness values among the study groups $(P=0.21)$, but a significant difference was noted after treatment $(P=0.009)$. Pairwise comparisons by Duncan test indicated that the application of sodium fluoride either alone or in combination with diode laser irradiation produced the highest microhardness value among the study groups $(p<0.05$; Table 1$)$.

-SEM analysis

In the control group, the natural appearance of enamel rods appeared to be faded away because of immersion in the demineralizing solution, which leads to the dissolution of mineral components (Fig 1a). In laser treated samples, the morphology of enamel was obviously different from the control group, because there were cracks, scratches, and porosities on the surface (Fig 1b). 
Table 1: The mean, standard deviation (SD) and the results of the statistical analysis regarding microhardness values before and after treatment in the experimental groups.

\begin{tabular}{|c|c|c|c|c|c|c|c|}
\hline \multirow{2}{*}{ Groups } & \multirow{2}{*}{ Definition } & \multicolumn{2}{|c|}{ Initial } & \multicolumn{2}{|c|}{ After treatment } & \multirow{2}{*}{$\begin{array}{c}\text { Pairwise } \\
\text { comparisons }\end{array}$} & \multirow{2}{*}{$P$-value (t test) } \\
\hline & & Mean & SD & Mean* & SD & & \\
\hline 1 & Control & 322.1 & 57.8 & 322.1 & 57.8 & a & - \\
\hline 2 & Laser & 341.2 & 76.0 & 366.3 & 56.9 & $a, b$ & 0.18 \\
\hline 3 & $2 \% \mathrm{NaF}$ & 363.3 & 68.9 & 412.3 & 50.6 & $\mathrm{c}$ & $<0.001^{*}$ \\
\hline 4 & MI Paste Plus & 302.2 & 58.6 & 357.7 & 51.4 & $a, b$ & $0.005^{*}$ \\
\hline 5 & Remin Pro ${ }^{\circledR}$ & 312.9 & 69.4 & 346.7 & 63.8 & $a, b$ & 0.11 \\
\hline 6 & $\mathrm{NaF}+$ Laser & 350.0 & 70.4 & 379.3 & 72.2 & $\mathrm{c}$ & $<0.001^{*}$ \\
\hline 7 & $\begin{array}{c}\text { MI Paste } \\
\text { Plus+ Laser }\end{array}$ & 305.7 & 71.4 & 339.8 & 47.7 & $a, b$ & $0.019^{*}$ \\
\hline 8 & $\begin{array}{l}\text { Remin Pro }{ }^{\circledR} \\
\quad+\text { Laser }\end{array}$ & 316.9 & 71.7 & 347.1 & 58.2 & $a, b$ & $0.039^{*}$ \\
\hline $\begin{array}{l}P \text { value } \\
\text { (ANOVA) }\end{array}$ & & \multicolumn{2}{|c|}{$P=0.217$} & \multicolumn{2}{|c|}{$P=0.009 *$} & & \\
\hline
\end{tabular}

*Indicates statistically significant difference at $p<0.05$.

When the remineralizing agents were applied on the surface without laser irradiation, some non-homogenous coatings with numerous granular or globular patterns masked the underlying enamel surface (Fig. 1c-e). The granular pattern of minerals was more obvious in the specimens treated with $\mathrm{NaF}$. In the groups which were treated with the combination of remineralizing agents and laser irradiation, a more obvious appearance of calcium phosphate in the form of separated or adherent granules was seen along with a lower degree of enamel cracks produced by the laser (Fig. 1f-h).

-EDX analysis

The mean values of minerals obtained from the two samples in the study groups are presented in Table 2. The fluorine content was greater in MI Paste Plus and Remin Pro groups, and the Phosphorus content was greater in Remin Pro ${ }^{\circledR}$ groups.

\section{Discussion}

The present study investigated the effect of different remineralizing agents either alone or combined with diode laser irradiation on microhardness of initial caries lesions. The surface microhardness test is generally proposed to assess the remineralizing efficacy of mineral agents through measuring surface strength (9). In the present study, microhardness assessment was performed in two stages; the first one was taken after tooth immersion in the demineralizing solution and the second one was obtained after the application of different remineralizing protocols. The lack of significant difference between groups after the first microhardness measurement confirms the presence of comparable enamel demineralization in the study groups. However, a significant difference in microhardness was observed after treatment among the groups. The application of $\mathrm{NaF}$ either alone or combined with laser irradiation was the most effective strategy to increase microhardness of WSLs. When the initial and final microharness values were compared in each study group, it was revealed that all remineralizing treatments caused a significant increase in microhardness, with the exception of Laser and Remin Pro ${ }^{\circledR}$ groups, which showed no significant difference after treatment.

In the present study, the application of an $810 \mathrm{~nm}$ diode laser at low power mode was not effective in enhancing microharness of WSLs. Previous studies generally used high power lasers such as $\mathrm{CO}_{2}, \mathrm{Nd}$ :YAG or Er:YAG lasers to enhance enamel resistance against caries attack (2,8-9,12,17-18). Different mechanisms have been proposed for caries-preventive effects of lasers. Some authors believe that laser irradiation leads to melting, fusion and resolidifaction of enamel crystals. Others assume that the reduction of water and carbonate content of enamel, the increase in hydroxyl ion content and the decomposition of enamel proteins are responsible for enhanced resistance against acid challenges $(17,19)$. The 


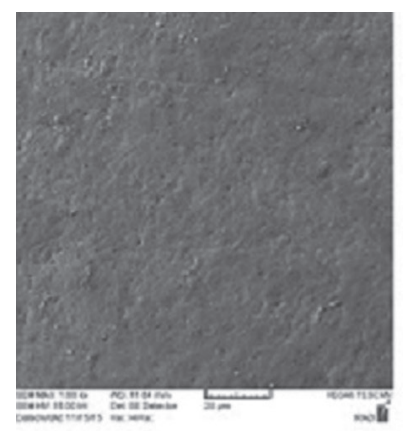

(a)

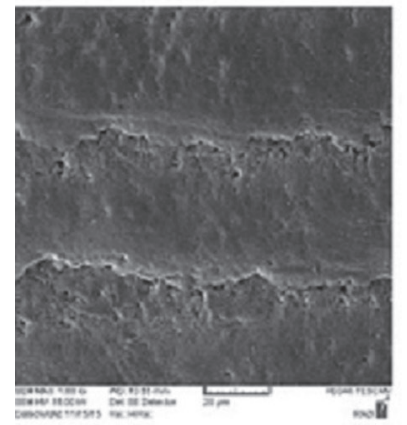

(e)

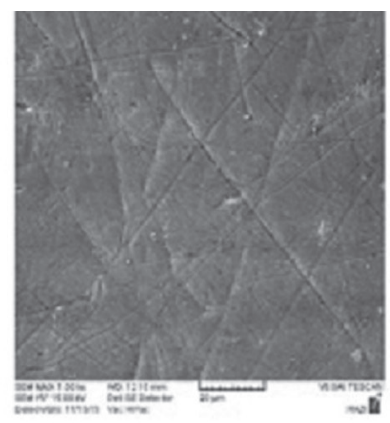

(b)

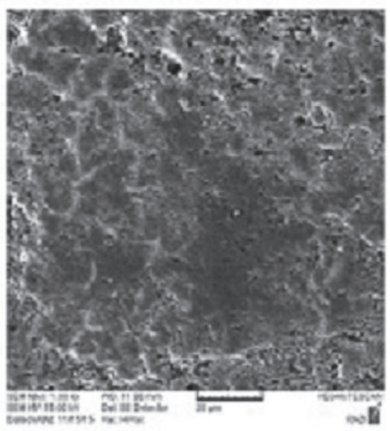

(f)

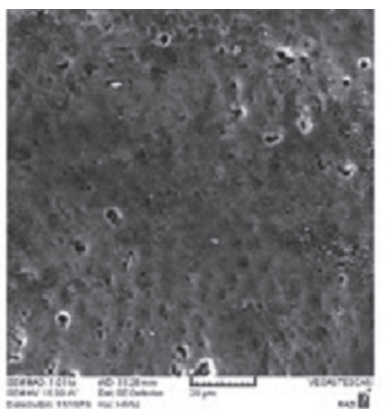

(c)

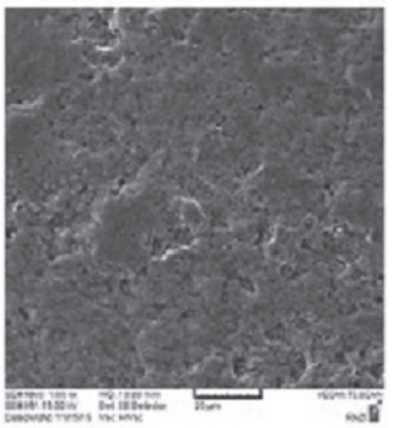

(g)

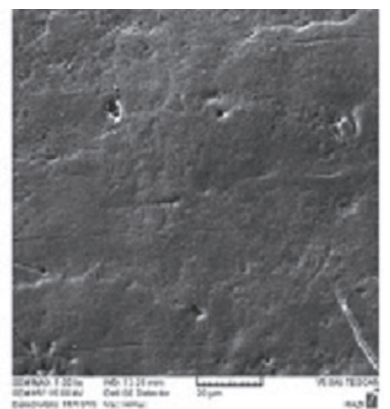

(d)

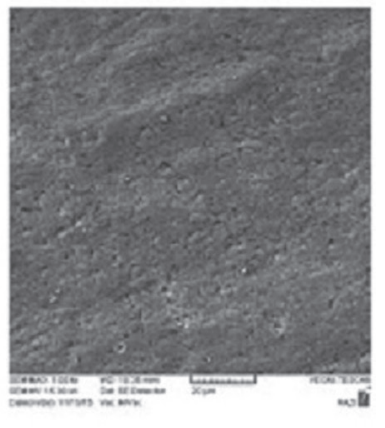

(h)

Fig. 1: SEM images of the representative specimens in the study groups after different surface treatments: (a) control, (b) Laser, (c) $2 \% \mathrm{NaF}$, (d) MI Paste Plus, (e) Remin Pro ${ }^{\circledR}$, (f) NaF + Laser (g) MI Paste Plus + Laser (h) Remin Pro ${ }^{\circledR}+$ Laser (SEM magnification 1.00 Kx).

Table 2: Comparison of some minerals (weight \%) in the study groups.

\begin{tabular}{|c|c|c|c|c|c|}
\hline Elements & Fluorine & Sodium & Phosphorus (P) & Calcium (Ca) & $\mathrm{Ca} / \mathbf{P}$ \\
\hline Groups & & & & & \\
\hline Control & 0.03 & 0.18 & 20.96 & 38.59 & 1.84 \\
\hline Laser & 0.04 & 0.00 & 20.35 & 41.39 & 2.03 \\
\hline $2 \% \mathrm{NaF}$ & 0.03 & 0.32 & 21.28 & 40.46 & 1.90 \\
\hline MI Paste Plus & 0.12 & 0.11 & 23.58 & 32.31 & 1.37 \\
\hline Remin Pro ${ }^{\circledR}$ & 0.11 & 0.00 & 29.16 & 35.85 & 1.22 \\
\hline $\mathrm{NaF}+$ Laser & 0.04 & 0.07 & 19.46 & 39.89 & 2.04 \\
\hline MI Paste Plus +Laser & 0.07 & 0.13 & 18.19 & 41.07 & 2.25 \\
\hline Remin Pro ${ }^{\circledR}+$ Laser & 0.02 & 0.07 & 26.17 & 46.87 & 1.79 \\
\hline
\end{tabular}


laser power used in this study was $500 \mathrm{~mW}$, which is the borderline between high power and low power lasers. Since the $810 \mathrm{~nm}$ diode laser has a low absorption band in tooth enamel, a photo-absorbing cream containing mineral agents was applied in this study before laser irradiation to enhance photochemical reactions and increase laser absorption by tooth structures. In some studies, $(3,14,20,21)$ Indocyanine green (ICG) was applied as a photo-absorbing agent combined with the infrared diode laser. In this study, a blue eatable dye was employed because it was very cheap and more accessible than ICG. SEM analysis revealed surface cracks and scratches produced as a result of laser irradiation on enamel surfaces. Since WSLs have a demineralized and weak surface, the effect of laser on creating cracks may be strengthened compared to healthy enamel. The alteration in laser parameters such as wavelength, power, pulse frequency and duration of irradiation may lead to different results, so further studies are suggested. The outcomes of this study are in agreement with those of Kato et al. (16) who reported that diode laser irradiation $(960 \mathrm{~nm}, 10 \mathrm{~Hz}, 6.5$ $\mathrm{W}, 33 \mathrm{~mJ}$ ) promoted a slight increase in calcium solubility. In contrast, De Sant'Anna et al. (3) revealed that the irradiation from an infrared diode laser $(\lambda=810 \mathrm{~nm}, 30$ $\mathrm{W}$ ) on deciduous tooth enamel using a photo-absorbing agent containing $2 \%$ sodium fluoride created reservoirs of minerals, which provided enamel protection against acid challenge during cariogenic activity phases.

In the present study, the groups treated with $2 \%$ sodium fluoride either alone or combined with laser irradiation presented the highest microhardness among the study groups. Although the caries preventive effect of fluoride-containing products has been largely described and understood, $(5,9,22,23)$ the anticariogenic potential of laser irradiation combined with fluoride treatment still remains controversial $(2,10,18,19,24-26)$. Several types of lasers have been used in combination with fluoride for prevention of enamel demineralization. Some authors believe that laser irradiation can increase binding of fluoride to tooth structure and lead to a significantly higher fluoride content in enamel (27). Others assume that the thermal effects of laser make several surface cracks which trap tooth minerals and fluoride ion in laser-irradiated substrate during a cariogenic challenge (11). However, the results obtained from this investigation showed that the diode laser irradiation through the photo-absorbing cream containing $2 \%$ sodium fluoride was not more effective than $2 \%$ sodium fluoride alone for enhancing microhardness of WSLs. This means that, laser irradiation did not show a synergistic effect with $\mathrm{NaF}$ on remineralization of incipient caries. The outcomes of this study are in line with those of Santaella et al. (28) who revealed that the fluoride varnish was more effective than diode laser application in enhancing the resistance of sound enamel. Similarly, Bahrololoomi et al. (13) revealed that the combined application of diode laser and topical fluoride varnish had no significant additional effect on enamel resistance to caries compared to fluoride varnish alone. Kato et al. (16) found that the additional application of 960 -nm diode laser to the fluoride treatment caused no significant increase or decrease in calcium solubility.

The use of CPP-ACP in recent years is growing as a useful method for prevention and treatment of enamel caries (8). It has been shown that CPP-ACP can stabilize calcium phosphate in dental plaque in the proximity of the teeth. In the presence of acid challenge, such as after each meal, CPP-ACP helps to maintain a supersaturated state of minerals with respect to tooth enamel and thus restricts mineral loss and assists remineralization of enamel subsurface lesions (22). MI Paste Plus consists of CPP-ACP and $900 \mathrm{ppm}$ fluoride. It is believed that the addition of fluoride into CPP-ACP enhances its remineralization potential on initial enamel lesions in comparison with either CPP-ACP or sodium fluoride alone (8). In the present study, the application of MI Paste Plus either alone or combined with laser irradiation caused a significant increase in microhardness of WSLs. But, the addition of laser irradiation to CPP-ACPF did not produce a synergistic effect in enhancing microhardness of WSLs.

Several studies confirmed the effectiveness of CPP-ACP containing agents in enamel remineralization. Salehzadeh et al. (7) found that the remineralization potential of MI Paste was significantly greater than sodium fluoride varnish and Remin Pro®. However, some studies presented no significant difference in inhibition of enamel caries between artificial saliva and MI Paste Plus $(11,22)$. The authors attributed the results to the short treatment application time (only two minutes) and immediately rinsing all remnants of the products after treatment $(11,22)$. The outcomes of this study confirm the results of Heravi et al. (15) who found that the combination of low power red and infra red lasers with CPP-ACPF provided no significant improvement in remineralization of enamel caries in comparison with CPP-ACPF alone.

In the present study, microhardness of WSLs increased after the application of Remin Pro ${ }^{\circledR}$, but the increase was not significant. Remin Pro ${ }^{\circledR}$ is a water-based cream that contains three components: hydroxyapatite, 1450 ppm of fluoride and xylitol as a sugar substitute with cariostatic properties. It is assumed that the ingredients in this topical agent enhance the potential of remineralization; limit the adhesion of bacterial plaque to enamel and reinforce the tooth against further carious attack (30). The outcomes of this study are similar to those of Mohan et al. (31) who showed an increase in mineral content when $\mathrm{CO} 2$ laser irradiation was done before and after the application of Remin Pro ${ }^{\circledR}$ paste on the enamel surface. The findings of this study are in contrast to 
the studies that reported the products containing fluoride and hydroxyapatite showed a higher remineralization effect than commercial products containing only fluoride (1000 and 1450 ppm) (5) or MI Paste Plus (4).

When Remin Pro was associated with laser irradiation, a significant improvement in microhardness of WSLs was obtained. This may be related to enamel ultrastructural changes that were induced by laser irradiation. SEM images indicated that after laser irradiation some micro cracks were produced on the enamel surface which could enhance mineral penetration into the crystalline structure of enamel and change the superficially loosely bonded minerals into firmly bounded ones.

According to SEM images, the laser-treated surfaces presented fissures, cracks, and more roughness compared to the control group. These surface defects are assumed to trap and precipitate mineral agents that are present near the tooth structure during a cariogenic attack. On the other hand, these surface defects can weaken the tooth structure and serve as a reservoir for bacterial adhesion. The application of mineral-containing agents on the surface leads to globular patterns of minerals, which were more obvious in $\mathrm{NaF}$ group. It seems that these surface coatings are able to provide a certain degree of protection against cariogenic challenge during mineral loss phase. When laser irradiation was combined with remineralizing agents, the detrimental effects of laser on the surface diminished. De Sant'Anna et al. (3) reported that after treatment of sound deciduous teeth with infrared diode laser through a photo-absorbing agent containing $2 \% \mathrm{NaF}$, a homogenous surface coating that masked typical enamel surface was observed. A similar appearance was obtained in the present SEM analysis in the groups treated with remineralizing agents. However, the combined application of diode laser and remineralizing agents lead to more protruded and well-defined granular or globular irregularities with opaque borders on the surface. It is believed that the immobilization of calcium, phosphate, and fluoride on the lased enamel produces these morphological features.

The EDX analysis revealed that the fluorine content was greater in MI Paste Plus and Remin Pro ${ }^{\circledR}$ groups, and the phosphorus content was greater in both Remin Pro ${ }^{\circledR}$ groups. Due to devoting only two samples for EDX analysis, it was not possible to achieve a clear conclusion regarding the percentage of minerals after different surface treatments. In the study of Mohan et al. (31) an increase in $\mathrm{Ca} / \mathrm{p}$ ratio was observed with the combination of laser irradiation and Remin Pro ${ }^{\circledR}$. This was attributed to the presence of hydroxyapatite crystals in this topical paste (30).

The association between remineralizing agents and laser irradiation can be a subject of interest in future studies. This in vitro study had certain limitations such as difficulty in simulating oral environment with the same re- mineralization and demineralization cycles, the salivary flow rate and oral protective factors including salivary proteins and bacteria. Further studies should be conducted to investigate the combination of other remineralizing agents with different laser settings in the clinical situations.

\section{Conclusions}

Under the conditions used in this study,

1. The application of $\mathrm{NaF}$ either alone or combined with laser irradiation was the most effective strategy for enhancing microhardness of WSLs.

2. The application of diode laser through photo-absorbing agents containing sodium fluoride or MI Paste Plus did not produce any additional effects in enhancing remineralization of WSLs

Although the combined application of diode laser with Remin Pro ${ }^{\circledR}$ was effective in enhancing microhardness of WSLs.

\section{References}

1. Gorton J, Featherstone JD. In vivo inhibition of demineralization around orthodontic brackets. Am J Orthod Dentofacial Orthop. 2003;123:10-4.

2. Stangler LP, Romano FL, Shirozaki MU, Galo R, Afonso AM, Borsatto $\mathrm{MC}$, et al. Microhardness of enamel adjacent to orthodontic brackets after CO2 laser irradiation and fluoride application. Braz Dent J. 2013;24:508-12.

3. De Sant'Anna GR, Paleari GSL, Duarte DA, Brugnera Jr A, Soares CP. Surface morphology of sound deciduous tooth enamel after application of a photo-absorbing cream and infrared low-level laser irradiation: an in vitro scanning electron microscopy study. Photomed Laser Surg. 2007;25:500-7.

4. Bilgin G, Yanikoglu F, Tagtekin D, Stookey G, Schemeron B. Remineraliza-tion potential of different agents and assessment by a new caries detection device. Gavin J Dent Sci. 2016;2016:39-43.

5. Gavrila L, Maxim A, Balan A, Stoleriu S, Sandu AV, Serban V, et al. Comparative study regarding the effect of different remineralizing products on primary and permanent teeth enamel caries lesions. Revista de Chimie. 2015;66:1159-61.

6. Oshiro M, Yamaguchi K, Takamizawa T, Inage H, Watanabe T, Irokawa A, et al. Effect of CPP-ACP paste on tooth mineralization: an FE-SEM study. J Oral Sci. 2007;49:115-20.

7. Salehzadeh Esfahani K, Mazaheri R, Pishevar L. Effects of treatment with various remineralizing agents on the microhardness of demineralized enamel surface. J Dent Res Dent Clin Dent Prospects. 2015;9:239-45.

8. Shetty S, Hegde MN, Bopanna TP. Enamel remineralization assessment after treatment with three different remineralizing agents using surface microhardness: An in vitro study. J Conserv Dent. 2014;17:4952.

9. Uysal T, Amasyali M, Koyuturk A, Ozcan S. Effects of different topical agents on enamel demineralization around orthodontic brackets: an in vivo and in vitro study. Aust Dent J. 2010;55:268-74.

10. Poosti M, Ahrari F, Moosavi H, Najjaran H. The effect of fractional $\mathrm{CO} 2$ laser irradiation on remineralization of enamel white spot lesions. Lasers Med Sci. 2014;29:1349-55.

11. Souza-Gabriel AE, Turssi CP, Colucci V, Tenuta LM, Serra MC, Corona SA. In situ study of the anticariogenic potential of fluoride varnish combined with $\mathrm{CO} 2$ laser on enamel. Arch Oral Biol. 2015;60:804-10.

12. Bedini R, Manzon L, Fratto G, Pecci R. Microhardness and morphological changes induced by Nd:Yag laser on dental enamel: an in vitro study. Ann Ist Super Sanita. 2010;46:168-72. 
13. Bahrololoomi Z, Lotfian M. Effect of diode laser irradiation combined with topical fluoride on enamel microhardness of primary teeth. J Dent (Tehran). 2015;12:85-9.

14. De Sant'anna GR, Dos Santos EAP, Soares LES, Do Espirito Santo AM, Martin AA, Duarte DA, et al. Dental enamel irradiated with infrared diode laser and photoabsorbing cream: Part 1-FT-Raman Study. Photomed Laser Surg. 2009;27:499-507.

15. Heravi F, Ahrari F, Mahdavi M, Basafa S. Comparative evaluation of the effect of Er:YAG laser and low level laser irradiation combined with CPP-ACPF cream on treatment of enamel caries. J Clin Exp Dent. 2014;6:e121-6.

16. Kato IT, Kohara EK, Sarkis JE, Wetter NU. Effects of 960-nm diode laser irradiation on calcium solubility of dental enamel: an in vitro study. Photomed Laser Ther. 2006;24:689-93.

17. Ahrari F, Poosti M, Motahari P. Enamel resistance to demineralization following Er:YAG laser etching for bonding orthodontic brackets. Dent Res J (Isfahan). 2012;9:472-7.

18. Esteves-Oliveira M, Pasaporti C, Heussen N, Eduardo CP, Lampert F, Apel C. Rehardening of acid-softened enamel and prevention of enamel softening through CO2 laser irradiation. J Dent. 2011;39:414-21. 19. Moosavi H, Ghorbanzadeh S, Ahrari F. Structural and morphological changes in human dentin after ablative and subablative Er:YAG Laser Irradiation. J Lasers Med Sci. 2016;7:86-91.

20. Ahrari F, Shahabi M, Fekrazad R, Eslami N, Mazhari F, Ghazvini K, Emrani N. Antimicrobial photodynamic therapy of Lactobacillus acidophilus by indocyanine green and 810-nm diode laser. Photodiagnosis Photodyn Ther. 2018

21. de Sant'Anna GR, dos Santos EAP, Soares LES, do Espírito Santo AM, Martin AA, Duarte DA, et al. Dental enamel irradiated with infrared diode laser and photo-absorbing cream: Part 2-EDX Study. Photomed Laser Surg. 2009;27:771-82.

22. Pulido M, Wefel J, Hernandez M, Denehy G, Guzman-Armstrong $\mathrm{S}$, Chalmers J, et al. The inhibitory effect of MI paste, fluoride and a combination of both on the progression of artificial caries-like lesions in enamel. Oper Dent. 2008;33:550-5.

23. Souza-Gabriel AE, Colucci V, Turssi CP, Serra MC, Corona SA. Microhardness and SEM after $\mathrm{CO}(2)$ laser irradiation or fluoride treatment in human and bovine enamel. Microsc Res Tech. 2010;73:10305.

24. Azevedo DT, Faraoni-Romano JJ, Derceli Jdos R, Palma-Dibb RG. Effect of Nd:YAG laser combined with fluoride on the prevention of primary tooth enamel demineralization. Braz Dent J. 2012;23:104-9.

25. Fornaini C, Brulat N, Milia G, Rockl A, Rocca JP. The use of sub-ablative Er:YAG laser irradiation in prevention of dental caries during orthodontic treatment. Laser Ther. 2014;23:173-81.

26. Zancope BR, Rodrigues LP, Parisotto TM, Steiner-Oliveira C, Rodrigues LK, Nobre-Dos-Santos M. CO2 laser irradiation enhances $\mathrm{CaF} 2$ formation and inhibits lesion progression on demineralized dental enamel-in vitro study. Lasers Med Sci. 2016;31:539-47.

27. Villalba-Moreno J, González-Rodríguez A, de Dios López-González J, Bolaños-Carmona MV, Pedraza-Muriel V. Increased fluoride uptake in human dental specimens treated with diode laser. Lasers Med Sci. 2007;22:137-42.

28. Santaella M, Braun A, Matson E, Frentzen M. Effect of diode laser and fluoride varnish on initial surface demineralization of primary dentition enamel: an in vitro study. Int J Paediatr Dent. 2004;14:199203

29. Heravi F, Ahrari F, Tanbakuchi B. Effectiveness of MI Paste Plus and Remin Pro on remineralization and color improvement of postorthodontic white spot lesions. Dent Res J (Isfahan). 2018 ;15:95-103.

30. Ebrahimi M, Mehrabkhani M, Ahrari F, Parisay I, Jahantigh M. The effects of three remineralizing agents on regression of white spot lesions in children: A two-week, single-blind, randomized clinical trial. J Clin Exp Dent. 2017;9:e641-8.

31. Mohan AG, Ebenezar AR, Ghani MF, Martina L, Narayanan A, Mony B. Surface and mineral changes of enamel with different remineralizing agents in conjunction with carbon-dioxide laser. Eur J Dent. $2014 ; 8: 118$
Acknowledgements

The authors would like to extend their gratitude towards the vice chancellor for research of Mashhad University of Medical Sciences for financially supporting this project (grant number 900095). The results presented in this paper have been taken from a student thesis (thesis number 2791)

\section{Conflict of interest}

The authors declare no potential conflicts of interest with respect to the authorship and/or publication of this article. 